\title{
Guest Editor's Remarks
}

\section{Journal of Biocommunication Special Issue on Legacies of Medicine in the Holocaust and the Pernkopf Atlas}

\author{
Leila Lax, B.A., BSc.A.A.M., M.Ed., Ph.D.
}

OPEN ACCESS

\section{Introduction}

Seventy-five years after the Holocaust, legacies of Nazi medicine remain, never resolved nor erased from our memories, and so we continue to be confronted by them. Through education about the Holocaust and the role of medicine within this history, through continued ethical discourse and documentation of current discoveries and recently revealed facts, perhaps the words "never again" will begin to resonate, and the adoption of new protocols may afford some dignity to those that perished.

This Special Issue of the Journal of Biocommunication $(J B C)$, the professional journal of the Association of Medical Illustrators and the BioCommunications Association, is published in acknowledgement of this dark time in our professional history and in recognition of controversies that emanate from the creation of Eduard Pernkopf's Atlas of Topographical and Applied Human Anatomy. The collection of resources in this Special Issue is intended to contribute to the current and future examination of this legacy, to advance scholarship and Holocaust education, in many contexts, including biomedical visualization.

Publication of this $J B C$ Special Issue is based on the Toronto Pernkopf Symposium (as it has become known colloquially), held at the University of Toronto, in Toronto, Canada, on November 10, 2019, and was formally titled, "The Vienna Protocol: Medicine's confrontation with the continuing legacies of its Nazi past." The Symposium proposal (Seidelman, et al., 2019) was submitted to the Sarah and Chaim Neuberger Holocaust Education Centre for inclusion in their 2019 Holocaust Education Week program and accepted for presentation. The proposal read:
Despite the revelations of the Nuremberg Medical Trial and subsequent prosecutions, the reality is that, with particular respect to medicine and the role of leading academic and scientific institutions during the so-called "Third Reich," the postwar period was marked by a "great silence." With few exceptions, this silence continued until the 1980 's, when increasing systematic scholarly research and inadvertent discoveries... revealed numerous atrocities.

A notable symbol of medicine's role in the Nazi period was Pernkopf's Atlas of Topographical and Applied Human Anatomy created at the Institute of Anatomy of the University of Vienna under contract to the publisher, Urban and Schwarzenberg. Numerous meticulous dissections of the human body were made, under the direction of Prof. Eduard Pernkopf, and were used as models for the creation of anatomical illustrations, exquisitely painted in watercolor, by Pernkopf's group of artists. These anatomical illustrations became internationally recognized for their exceptional clarity, unprecedented detail, and aesthetic beauty. The atlas was the first ever to have been produced using modern fourcolor printing technology and proved so popular that it was published in eight languages. Not fully appreciated until the mid 1980's was the fact that many of the paintings included Nazi symbols (swastikas and SS runes) in the signatures of the artists. These revelations resulted in a special investigation by the Senate of the University of Vienna, documenting that the bodies of over 1300 executed victims of the Nazi "legal" court system in Vienna were delivered to the Institute of Anatomy, an unknown number of which were portrayed in the atlas. In response, the publisher discontinued production of the atlas. Copies remain in private and university collections, 
and digital version of the images are easily obtained on the Internet (Seidelman et al., 2019).

\section{The 2019 Symposium}

The Symposium highlighted The Vienna Protocol (2017), a landmark document, authored by Rabbi Joseph Polak with the assistance of Prof. Michael Grodin, that makes recommendations for handling of recent and ongoing discoveries of human remains related to the Holocaust and is applicable in other contexts of human rights abuse. The Untermann Protocol within The Vienna Protocol addresses the use of "data" and images from victims of Nazi terror, specifically the anatomical images in the Pernkopf atlas. Symposium presenters, Dr. William Seidelman, Dr. Sabine Hildebrandt, Dr. Susan Mackinnon, and Dr. Andrew Yee, were involved in requesting the review of the issues that resulted in The Vienna Protocol responsum.

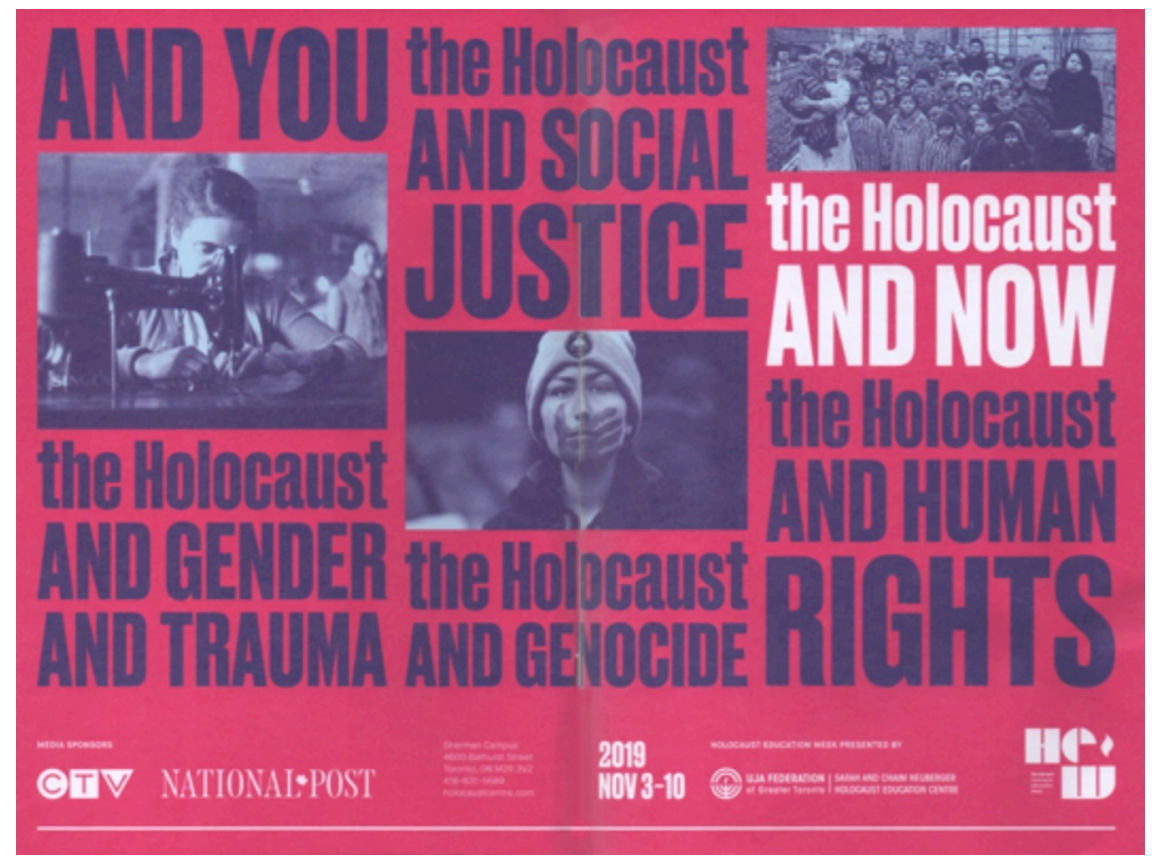

Figure 1. Holocaust Education Week 2019 catalogue of events. (Credit: Sarah and Chaim Neuberger Holocaust Education Centre, Toronto, Canada) contribute to the Symposium. I want to thank my colleagues in Biomedical Communications, Institute of Medical Science, in the Temerty Faculty of Medicine, at the University of Toronto, for their gracious support and generous funding of this endeavor. All presentations were video recorded and posted on my Symposium Website (https://www.leilalax.ca/research/pernkopf-symposium). Feedback on the Symposium was extremely positive, so I decided to propose publication of these papers in the $J B C$. I am grateful to all presenters for editing their video transcripts to create publishable papers, adding details, references and refining text as required for this $J B C$ Special Issue. I also want to thank Dr. Sabine Hildebrandt for her excellent summary of the Symposium published in the Annals of Anatomy (2020)

(https://doi.org/10.1016/j.aanat.2020.151459).

\section{The $2021 J B C$ Special Issue}

I sincerely appreciate the support of the $J B C$ Management Board for their dedication to scholarship and the publication of this Special Issue on the legacy of the Pernkopf atlas that contributes to the historical record and acknowledges our role, as medical artists, in addressing this almost-forgotten period in our profession. I particularly want to thank Gary Schnitz, Editor-in-Chief of the $J B C$, whose hard work, dedication to details and professionalism brought this Special Issue to fruition. Gary graciously shared his knowledge and expertise, and I thank him for an exceptional collaborative experience. I am grateful to my AMI colleague, Kathy Jung for her early support of this project. April Ingram, Managing Editor of the $J B C$, provided helpful feedback on each Symposium paper. Approvals for the use of images from the atlas, for this Special Issue, were graciously provided by the Josephinum,
The Neuberger Holocaust Education Centre advertised the Symposium, in print (Figure 1) and online in their Holocaust Education Week 2019 Website, (https://www.holocaustcentre.com/hew-2019/the-viennaprotocol). The Symposium was held in a lecture hall in the Medical Sciences Building at the University of Toronto and was well attended. It was an honor for me, as a faculty member in the Master of Science program in Biomedical Communications, to organize, moderate, and
Medical University of Vienna, organized by Professor Herwig Czech and Professor Christiane Druml, and researched by Daniela Hahn. I am enormously grateful to have had the opportunity to work with the distinguished group of international and local scholars represented in this Special Issue. On a personal note, through this work, I remember my parents, Bella and Irving Goldstein, who were Holocaust Survivors, and I thank my husband Gary, and children, Ryan, Ilyse and Jonah, and Isaac and Anna, 
and dear friends, for sharing their strength and inspiration with me. I am honored to be the Guest Editor of this $J B C$ Special Issue.

This $J B C$ Special Issue is composed of six historical papers, seven papers based on the Symposium, two papers from the Medical University of Vienna and one document for owners and users of the atlas, also from the Medical University of Vienna. The Symposium presenters and now, authors, of this Special Issue, share with us their individual and collective expertise, their resolve to tackle what is difficult and their determination to make a difference. Their advocacy has changed history. Their scholarship informs us and resonates in contemporary Holocaust education, providing ethically relevant, thought-provoking questions.

Here is the list of authors, in order of Symposium presentation, reflected within this Special Issue:

Susan Mackinnon, M.D., Chief of the Division of Plastic and Reconstructive Surgery, Washington University, St. Louis, Missouri, in her presentation/paper titled, "Before and After I Knew: Disclosure, Respect, Gratitude and Solemnity, "explains how the atlas is an informative resource that she uses, when needed, during surgery. Upon finding out about the history of the atlas, she tells us about the ethical dilemma she faced, to use or not use the atlas. The questions raised by Dr. Mackinnon and her colleague, Dr. Andrew Yee (2019a, 2019b) led to an important research study and numerous publications highlighting the history of the atlas and the problematic ethics around it. Her explication of this dilemma was essential to the discourse and recommendations made in The Vienna Protocol, for the ethical use of the atlas.

Rabbi Joseph Polak, Chief Rabbi of the Rabbinical Council of the Commonwealth of Massachusetts and New England, Boston, Massachusetts, with the assistance of Michael Grodin, Professor of Health Law, Ethics and Human Rights, Boston University, were responsible for the creation of The Vienna Protocol (2017). In Rabbi Polak's presentation/paper titled, "The Vienna Protocol and Reflections on Nazi Medicine: Murder à la Carte," asks important questions regarding the role of doctors as healers and how their professional identity changed during the Holocaust, in some cases, to become "murderers." We struggle to understand, how the Hippocratic Oath to heal can be compatible with the harm done in Nazi medicine and in human experiments for the so called good of science. Similarly, Rabbi Polak also refers to the "artist as murderer." How is it possible to admire the aesthetic beauty and anatomical accuracy of the images in the atlas, knowing that Pernkopf, and his artists, Lepier, Batke, Endtresser and Schrott were active members or sympathizers of the Nazi party? How is it possible to make sense of this disparity in identity? How does this change what we see in the atlas? How must this change the way we use the atlas?

William E Seidelman, M.D., Emeritus Professor, Department of Family and Community Medicine, Temerty Faculty of Medicine, University of Toronto, whose presentation/paper is titled, "The Role of German Academic Medicine and Science in the Medical Crimes of the Third Reich and the Shoah: The Continuing Legacy," informs us about the history of medicine in the Holocaust. His advocacy for reparations, historical accuracy, and scholarly documentation of medicine in the Holocaust over the last 30 years deserves much credit. He has worked tirelessly with scholars and politicians to activate change, add to the historical record and achieve acknowledgement of the victims of Nazi terror. Dr. Seidelman was instrumental in organizing the meeting at Yad Vashem in May 2017, a Special Symposium of internationally noted experts in the field, where The Vienna Protocol was formally presented for the first time. (Please note, Dr. Seidelman could not attend the Symposium in Toronto in person and presented via previously recorded video.)

Sabine Hildebrandt, M.D., Associate Professor of Pediatrics at Boston Children's Hospital and anatomy educator at Harvard Medical School, provides a detailed historical overview of the Holocaust medicine and current findings in her presentation/paper titled, "Anatomy in Nazi Germany: The use of victims' bodies in academia and present-day legacies. "She is an international authority in the field and has published a comprehensively researched book titled, "The Anatomy of Murder" (2016) and recently edited and contributed to a new book with international scholars, called "Recognizing the Past in the Present: New studies on medicine before, during, and after the Holocaust" (2021). Dr.

Hildebrandt's dedication to research, recording and dissemination of the history of medicine in the Holocaust and ethical examination of difficult issues, promises continuity of scholarship of notable complexity.

Philip Berger M.D., Professor, Family and Community Medicine, Temerty Faculty of Medicine, University of Toronto, in his presentation/paper titled, "Canadian Physicians' Breach of Duty to Patients and Communities from the Acquisition of Indigenous Skulls in the 19th Century to the Abandonment of People with AIDS in the 20th Century" reminds us of the similarities in Holocaust 
atrocities to situations in more recent history, in Canada and internationally. His focus on physicians' breach of duty and medical ethics continues to be relevant in numerous contexts. Leading by example, through tracking and contributing to the identification of two Indigenous skulls from Canada in Rudolf Virchow's skeletal collection held in Berlin, he demonstrates what is possible and how much more can be done. His commentary on the human condition begs the question: Is it our destiny that history will continue to repeat itself?

Anne Agur Ph.D., Professor, Department of Anatomy, Temerty Faculty of Medicine, University of Toronto, in her presentation/paper titled, "Anatomical Detail and Accuracy of the Pernkopf Atlas and Examples of Clinical Impact," clarifies the medical orientation of the Pernkopf atlas anatomical illustrations, demonstrating the layered, stratified visualizations of the clunial nerves. She traces the nerves and their relationship to the surrounding structures through 5 illustrations, from superficial to deep. Her explanation provides another example, like Dr. Mackinnon's, of the meticulously rendered anatomical illustrations in the atlas that enable medical and surgical practitioners to visualize the most detailed structures, that can be helpful in patient diagnosis and surgical repair.

Leila Lax Ph.D., Assistant Professor, Biomedical Communications, Institute of Medical Science, Temerty Faculty of Medicine, University of Toronto, in her presentation/paper titled, "Towards Informed Use of the Pernkopf Atlas," calls for an updated information letter to be inserted in all volumes, a research study on ethical use of the atlas in the medical art community, and a permanent exhibit of the original anatomical illustrations for continued scholarship and Holocaust education. She also explains that in academia, when the atlas is being considered for use in the medical art context, e.g. for surgical visualization reference or for scholarly discourses on ethics in medical art history, the integration of the Untermann Protocol from The Vienna Protocol (2017), is essential. The history of the atlas and the victims' depicted must be communicated to students before use, to enable students to make an informed decision and consent to use and their participation.

To provide historical scaffolding and contextualize this Special Issue, I selected a few previously published scholarly papers, that are reprinted in the first section, including: (1) Prof. David Williams' (1988) seminal paper on Pernkopf and his artists, originally published in the $J B C$; (2) Daniela Angetter's (2000) Senate report from the University of Vienna; (3) Dr. William Seidelman's (2012) historical overview; (4) Dr. Sabine Hildebrandt's (2016) chapter on "The Pernkopf Controversy" from her book, The Anatomy of Murder; (5) Dr. Andrew Yee, Dr. Susan Mackinnon and colleagues' (2019a) research study with nerve surgeons that prompted the recent ethical debate "to use or not to use" the Pernkopf atlas; and (6) The Vienna Protocol (2017) created by Rabbi Joseph Polak with the assistance of Prof. Michael Grodin, that addresses issues pertaining to the handling of human remains in continuing discoveries and the ethical use of the Pernkopf atlas.

Shortly after the Symposium I received emails from Dr. Susan Mackinnon and Dr. Sabine Hildebrandt with the exceptional news that negotiations for the donation and repatriation of the original Pernkopf anatomical illustrations, owned by Elsevier, held in Munich, were underway. In summer of 2020 the Pernkopf watercolors were transferred to the Medical University of Vienna for archival and display purposes at the Josephinum, the History of Medicine Museum. Dr. Herwig Czech, Professor of Medical History at the Medical University of Vienna and curator of the collection, Professor Christiane Druml, Director of the Josephinum, and Rector Markus Müller and colleagues documented this important donation in their paper published in January 2021 in the Annals of Anatomy.

I am sincerely appreciative of the important contributions to this Special Issue from the Medical University of Vienna. Professor Druml's impactful lecture on the occasion of the University's Memorial Day, March 12, 2021 pays tribute to "all those who were victimized by the National Socialist regime in Austria", acknowledges the history of the atlas and announces Elsevier's gracious donation of the Pernkopf anatomical illustrations to the Josephinum.

Professors Herwig Czech, Christiane Druml, Wolfgang Weninger and Rector Markus Müller, in their paper titled, "What Should be Done with Pernkopf's Anatomical Illustrations? A Commentary from the Medical University of Vienna," provide their meaningful perspective that out of respect for the victims, use of Pernkopf's atlas should not be promoted or perpetuated in medical education and given its tainted history, they recommend that atlas be replaced with other resources wherever possible. They acknowledge individual responsibility for use, as in surgery or clincial medicine, to improve or save the life of a patient, as well as, use for scholarly purposes in Holocaust and ethics education.

The Special Issue concludes with the important publication for worldwide dissemination of a significant document, authored by Rector Markus Müller and 
Professor Christiane Druml, on behalf of the Medical University of Vienna, titled "Note to the Users of Pernkopf's Atlas of Topographical and Applied Human Anatomy," dated July 1, 2021. This document is intentionally published as an open access PDF, to be downloaded and printed. Please insert this document in all volumes of the atlas in your personal or institutional reference collections. This important document acknowledges the history of the atlas and the Medical University of Vienna's perspective on use.

\section{New Questions}

Scholarly initiatives answer some questions and really stimulating scholarly initiatives give rise to many new questions. An important question that I was recently asked is: "Why can the Pernkopf atlas not be reproduced and replaced today with digital images?" My answer is: Technically it is possible, but practically it will be challenging to achieve; an anatomical atlas with similar high-level detail will be created differently in this digital age. Pernkopf's atlas was created with huge costs in time, money and tragic loss of human life.

In terms of time, the Pernkopf atlas took approximately twenty-five years to create. With the events of the 1938 annexation of Austria into Nazi Germany and World War II, it is unclear how much work was done on the atlas during that period and how much time Pernkopf and his four main artists, Lepier, Batke, Endtresser and Schrott dedicated to their participation in the Nazi regime or spent at the warfront. Pernkopf signed the contract with publishers, Urban \& Schwarzenburg, and began work on the first volume of the atlas in 1933; it was published in 1937. The second volume was published in 1941 and the third in 1952. Pernkopf died in 1955 and the first book of the fourth volume was completed in 1956-57, with the assistance of anatomist Werner Platzer; the second book of this volume was published in 1960 (Czech et al, 2021; Williams 1988). After Pernkopf's and Batke's postwar imprisonment for their Nazi activities, they, Lepier and Endtresser, were "de-Nazified" and returned to their work on the atlas at the Anatomical Institute at the University of Vienna.

The financial cost of the group of artists and anatomical dissectors (not much is known about the dissectors) working on the atlas for that extended period of time would have been substantial and was supported by Urban and Schwarzenberg and the University of Vienna.
The biggest cost was the tragic loss of human life. As indicated by the University of Vienna Senatorial Report (Angetter, 2000), a minimum of 1377 bodies of executed persons were delivered to the Anatomical Institute at the University of Vienna. Many of the bodies portrayed in the atlas are of healthy, young and middle age adults. It is acknowledged that some were victims of political terror. This is the primary reason why the atlas will never be recreated - because of the horrific number of bodies healthy bodies of victims - that were used to create the detailed dissections and illustrations.

Technically, in recent years, 3-dimensional, digital, anatomical images and datasets have been created, but not to the extent seen in the atlas. For example, the American, National Library of Medicine's Visible Human Project, of a male body and a female body, are very helpful anatomical resources. However, the male data set is ethically problematic, as it derives from a man executed for murder in Texas in 1993. The Visible Human Project digital images were created by a series of cross-sectional cryosection, CT, and MRI images. It must be emphasized that the male and female bodies are only visual datasets. They are not didactic visualizations. Working with these radiographic datasets requires interpretation of structures, elimination of artifacts, 3-dimensional representation, static and/or animated rendering, and detailed labelling to become purposeful anatomical education resources. Currently there are many large and small scale government research projects underway that provide, and continue to improve, digital anatomical educational resources, such as the next generation of the Visible Human Project: From Data to Knowledge (https://www.nlm.nih.gov/research/visible/data2knowledg e.html) and numerous other initiatives based on these datasets

(https://www.nlm.nih.gov/research/visible/products.html), as well as others that are commercial initiatives, such as the Visible Body (https://www.visiblebody.com) and Elsevier's Complete Anatomy Series (https://3d4medical.com). These digital resources do not provide the super-realistic anatomical visualizations and ultra-detailed labelling like Pernkopf's atlas. They differ in pedagogic design and they have their own merits. These educational tools are designed with attributes, like $3 \mathrm{D}$ rotational visualizations, topographic transparencies and functional anatomy descriptions. Thus, technically the Pernkopf atlas may be replaced by new digital atlases, but they will be different and not produced in the same way, at the same costs - especially to human life. 


\section{Holocaust Education Initiatives}

It is my hope that this $J B C$ Special Issue will help inform those who do not know, will help clarify for those who do know, and will help future generations reflect on previously unrecognizable facts and features of the Pernkopf legacy (Figures 2-4). It is in this way that we can honor those who lost their lives, the nameless victims forever portrayed in the atlas.

In recent years there have been resounding calls for Holocaust education. An influential article by Dr. Richard Horton, Editor of The Lancet, titled "Medicine and the Holocaust - it's time to teach," was published in 2019. The 2020 Remembrance Day webinar, led by Dr. Horton, called "Foundations: Physicians, Human Rights, and Civil Liberties: Lessons from the Holocaust"

(http://daradocs.org/webinar/), was conducted on behalf of Doctors Against Racism and Antisemitism and the Ontario Medical Association. That same day, on November 11, 2020, for the first time, the second-year medical class at the University of Toronto had a special session on Holocaust medicine. Dean Trevor Young's announcement read:

While this topic is deeply unsettling, we believe that understanding the darkest parts of the history of medicine - in all of its unsanitized, grotesque forms is critical to developing moral courage and integrity as a physician

(https://medicine.utoronto.ca/news/cultivating-moralcourage).

In 2021, the Lancet Commission on Medicine and the Holocaust, envisioned by Dr. Horton and Dr. Seidelman, was formed. It is co-chaired by Prof. Volker Roelcke of the Institute for the History of Medicine of the University of Giessen, Germany, Prof. Sabine Hildebrandt of Harvard Medical School, U.S.A. and Prof. Shmuel Reis of the Faculty of Medicine of the Hebrew University, Israel.

In the near future, we anticipate the installation of an exhibit of the Pernkopf anatomical illustrations at the Josephinum, Medical University of Vienna. Over the coming years, we look forward to the creation of new Holocaust education opportunities to elevate knowledge and awareness, improve recognition and practices, and enhance integration of The Vienna Protocol for the ethical handling of continued discoveries of past and present atrocities worldwide.

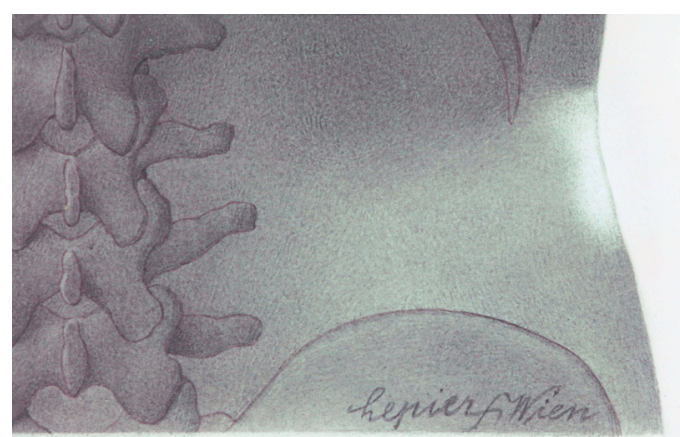

Figure 2. Lepier's signature with a swastika. Image credit: $M U W-Z E-003250-0005-0466$.

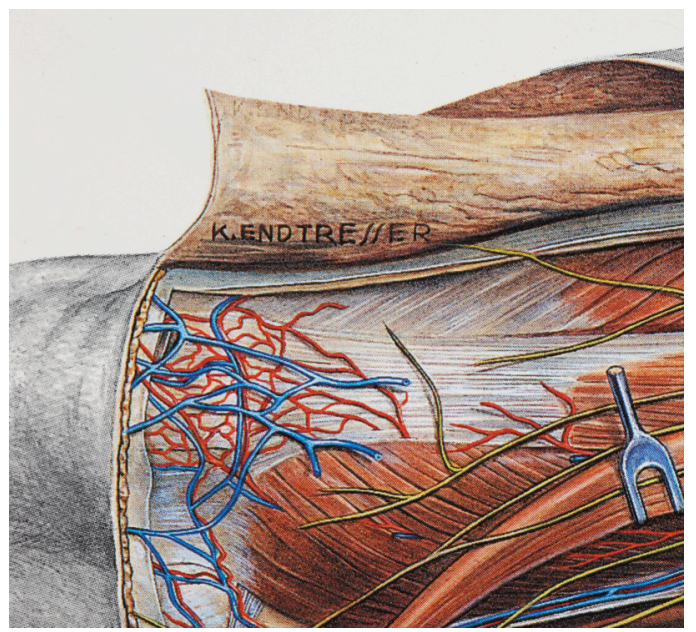

Figure 3. Endtesser's signature with the slanted "SS." Image credit: $M U W$-Andruck-33611-Seite1.

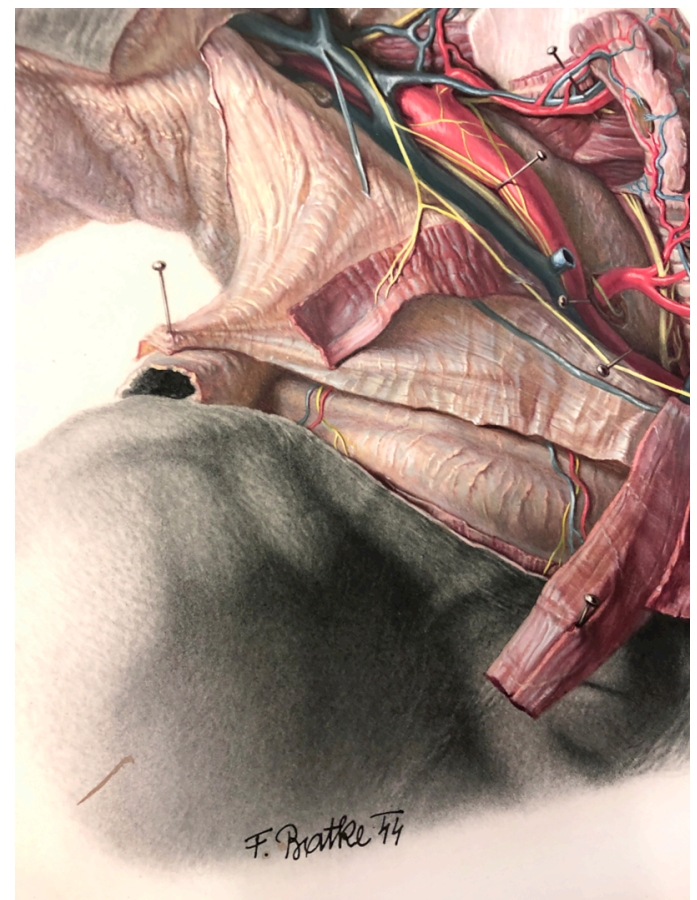

Figure 4. Batke's signature dated "44" like the lightning bolts of the schutzstaffel. Image credit: MUW-ZE-003250-0005-0538r. 
In academia, particularly in the contexts of medical visualization and scholarly discourses on ethics, the adoption of the Untermann Protocol, from The Vienna Protocol, for appropriate communication of the history and informed consent on use of the Pernkopf atlas, is a necessity. The 2021 Note to the Users of Pernkopf's Atlas of Topographical and Applied Human Anatomy, from the Medical University of Vienna, published herein, will be helpful in these educational contexts.

\section{The $J B C$ Collection of Holocaust Education Resources and the Pernkopf Legacy}

This $J B C$ Special Issue was intentionally created as an open-access collection of educational resources and most of the resources are freely available for you to use in your Holocaust education initiatives and pedagogic endeavors. The HTML files and PDFs of authors' papers are marked at the start of each article with an open-access icon. The Symposium presentation videos are available at the end of each authors' HTML file and are also freely available for your educational use.

Four of the previously published papers are not openaccess and therefore not for reproduction, distribution, or commercial use without the written expressed permission of the original publisher and they are:

- Angetter, D.C. 2000. Anatomical science at the University of Vienna 1938-45. Lancet. 355:1445-57.

- Seidelman, W.E. 2012. Dissecting the History of Anatomy in the Third Reich - 1989-2010. Annals of Anatomy. 194:228-236.

- Hildebrandt, S. 2016. The Pernkopf Controversy. In, The Anatomy of Murder: Ethical Transgressions and Anatomical Science during the Third Reich. New York: Berghahn Books.

- Yee, A., Coombs, D., Hildebrandt, S., Seidelman, W.E., Coert, J.H., Mackinnon, S.E. 2019a. Nerve surgeons' assessment of the role of Eduard Pernkopf's atlas of topographical and applied human anatomy in surgical practice. Neurosurgery. 84(2):491-498.

The 2021 Note to the Users of Pernkopf's Atlas of Topographical and Applied Human Anatomy is an openaccess, freely available document, and we ask that you print and insert a copy of it, in all volumes of your personal and/or institutional editions of the atlas. This document can be also used by educators, researchers, museums, etc. to communicate to individuals the history of the atlas, in advance of viewing or using the atlas, to provide an ethical approach to individual decisionmaking and informed consent to use.

Please cite the open-access resources you use from this $J B C$ Special Issue 2021 collection and send me an email at1.lax@utoronto.ca, so that I can record the use of our resources in your educational initiatives.

As the Guest Editor of this $J B C$ Special Issue and as a member of the Association of Medical Illustrators, I acknowledge this dark part of the history of our profession, and I am grateful for the opportunity to contribute to current scholarship, and future Holocaust and ethics education.

\section{Conclusion}

The lessons to be learned from the Holocaust remain poignant and relevant - facts continue to be revealed, things previously hidden continue to emerge, the formerly silenced past perhaps now has the benefit of time and space to be heard. New transparencies in research, scholarship, discourse, documentation, dissemination and education will continue to inform us. This $J B C$ Special Issue is a collection of openly accessible, scholarly resources that you are welcome to use in your Holocaust education initiatives or for your personal reflection. These educational resources are provided to help deepen our understanding of the inherent ethical complexities and controversies in this dark history. The issues remain relevant because they are impossible to resolve. And thus, the past remains present, and we continue to confront it.

This $J B C$ Special Issue was created to facilitate new scholarly discourses within the medical art community, in practice and in academe, as well as more broadly, in medicine and health professions education, and other research and pedagogic contexts, for all people, of all ages. As readers of this $J B C$ Special Issue, I hope you will be inspired to examine the historical record through a contemporary lens, and that the legacies of medicine in the Holocaust and the Pernkopf atlas will bring new insights, especially into personal and professional ethics and integrity.

In conclusion, the atlas reminds us that

...it is indeed the cadavers (or victims?) themselves that teach us... by speaking in a quiet and elegant way to subsequent generations...they not only teach 
anatomy; they remind us that ignorance and prejudice and hatred are not necessarily mitigated by knowledge or (level of) education.

...Let them remind us of the sacrifices that have been made that we might practice our art. And above all, let them remind us of suffering not only in the past, but in the present, that we may be more compassionate physicians, more compassionate citizens of the world (Riggs 1998).

\section{Dedication}

I dedicate this Special Issue of the Journal of Biocommuncation to the Holocaust victims portrayed in the atlas, who remain nameless, but not unknown - may they always be remembered.

\section{References}

Angetter, D.C. 2000. Anatomical science at the University of Vienna 1938-45. Lancet. 355:1445-57. https://doi.org/10.1016/s0140-6736(00)02151-6.

Czech, H., Druml, C., Müller, M, Voegler, M., Beilmann, A., Fowler, N. 2021. The Medical University of Vienna and the legacy of Pernkopf's anatomical atlas: Elsevier's donation of the original drawings to the Josephinum. Annals of Anatomy. Accessed at: https://doi.org/10.1016/j.aanat.2021.151693.

Hildebrandt, S. 2016. The Anatomy of Murder: Ethical Transgressions and Anatomical Science during the Third Reich. New York: Berghahn Books.

Hildebrandt, S. 2020. The Vienna Protocol: Medicine's confrontation with continuing legacies of its Nazi past. Annals of Anatomy. 229:151459. Published online January 20, 2020. Accessed at: https://doi.org/10.1016/j.aanat.2020.151459

Hildebrandt, S., Offer, M., Grodin, M.A. (Eds.). 2021. Recognizing the past in the present: New studies on medicine before, during, and after the Holocaust. New York: Berghahn Books. Horton, R. 2019. Offline: Medicine and the Holocaust - it's time to teach. Lancet. 394 (10193): 105.
Lax, L. 2020. The Toronto Pernkopf Symposium Presentation videos from Neuberger Holocaust Education Week Symposium (Nov. 10, 2019). Published at: https://www.leilalax.ca/research/pernkopf-symposium.

National Library of Medicine. The Visible Human Project: From Data to Knowledge. Access on June 30, 2021 at:

https://www.nlm.nih.gov/research/visible/data2knowledg e.html and Projects Based on the Visible Human Data Set. Accessed on June 30, 2021 at: https://www.nlm.nih.gov/research/visible/products.html

Pernkopf, Eduard. 1980. Atlas of Topographical and Applied Human Anatomy. Volume 1: Head and Neck; Volume 2: Thorax, Abdomen and Extremities, Baltimore and Munich: Urban \& Schwarzenberg.

Polak, J.A. 2017. The Vienna Protocol: for when Jewish or Possibly-Jewish Human Remains are Discovered. In: Seidelman, W.E., Elbaum, L., Hildebrandt, S. (Eds.), How to deal with Holocaust era human remains:

Recommendations arising from a special symposium. Elie Wiesel Center for Jewish Studies, Boston University, Boston, MA. Accessed at:

http://www.bu.edu/jewishstudies/files/2018/08/HOW-

TO-DEAL-WITH-HOLOCAUST-ERA-

REMAINS.FINAL .pdf

Riggs G. 1998. What should we do about Eduard Pernkopf's atlas? Academic Medicine. 73(4):380-386.

Roelcke, V., Hildebrandt, S., Reis, S. 2021. Announcing the Lancet Commission on medicine and the Holocaust: Historical evidence, implications for today, teaching for tomorrow. The Lancet. 397(10277):862-864. Accessed at: https://doi.org/10.1016/S0140-6736(21)00157-4

Seidelman, W.E. 2012. Dissecting the History of Anatomy in the Third Reich - 1989-2010. Annals of Anatomy. 194:228-236.

Seidelman, W.E., Hildebrandt, S., Mackinnon, S., Polak, J., Agur, A., Berger, P., Lax, L. 2019. The Vienna Protocol: Medicine's confrontation with continuing legacies of its Nazi past. Holocaust Education Week Symposium, Neuberger Holocaust Education Centre. Nov. 10, 2019. Accessed at: https://www.holocaustcentre.com/hew-2019/the-viennaprotocol 
Williams, D.J. 1988. The history of Eduard Pernkopf's Topographische Anatomie des Menschen. Journal of Biocommunication. 15(2):2-12.

Yee, A., Coombs, D., Hildebrandt, S., Seidelman, W.E., Coert, J.H., Mackinnon, S.E. 2019a. Nerve surgeons' assessment of the role of Eduard Pernkopf's atlas of topographical and applied human anatomy in surgical practice. Neurosurgery. 84(2):491-498. Accessed at: https://doi.org/10.1093/neuros/nyy159

Yee, A., Zubovic, E., Yu, J., Ray, S., Hildebrandt, S., Seidelman, W.E., Polak, J.A., Grodin, M., Coert, J.H., Brown, D., Kodner, I.J., Mackinnon, S.E. 2019b. Ethical considerations in the use of Pernkopf's atlas of anatomy: A surgical case study. Surgery. 165(5):860-867. Accessed at: https://wustlchess.azurewebsites.net/wpcontent/uploads/2019/11/Ethical-considerations-in-theuse-of-Pernkopf-s-Atlas-of-Anatomy- 2019 Surge.pdf

\section{About the Author}

Leila Lax, an assistant professor in the Master of Science program in Biomedical Communications, Institute of Medical Science, Faculty of Medicine, University of Toronto, recently retired from teaching after 37 years. Leila taught courses in medical legal visualization and conducted large-scale, curricular design research in medical, interprofessional and health sciences education. She held the 2-time distinction of AMI Commissioner on the Accreditation Review Committee for the Medical Illustrator. Leila's masters and doctoral degrees are in Higher Education with specializations in health professions education and collaborative knowledge building. As a Senior Research Scientist, Institute for Knowledge Innovation and Technology, she continues to coordinate the Palliative Care eLearning Program. Leila's work has been recognized by numerous awards, since her early days as a medical illustrator, for her teaching, research, publications, and co-design curricular initiatives. In 2021, Leila was honored with an Ontario Government Volunteer Recognition Award.

Leila Lax, B.A., B.Sc.A.A.M., M.Ed., Ph.D.

Assistant Professor (retired), Biomedical Communications, Institute of Medical Science, Temerty Faculty of Medicine, University of Toronto Contact:1.1ax@,utoronto.ca

\section{Image Credit}

The Journal of Biocommunication wishes to thank the Josephinum and the Medical University of Vienna for approving the publication of Pernkopf atlas images that are used within this Special Issue. These images may appear on the cover, in the Table of Contents, and as figures within articles and are acknowledged with the following image credit:

\section{Josephinum - Ethik, Sammlungen und Geschichte der Medizin, MedUni Wien}

\section{Josephinum - Ethics, Collections and History of Medicine, MedUni Vienna}

\section{Licensing}

The author has chosen to license this content under a Creative Commons Attribution, NonCommercial, NoDerivatives 4.0 International License.

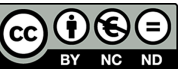

Authorization for publication of images from Pernkopf's atlas has been granted for use in this article only. The atlas images must remain within the context of this article for open-access, scholarship and educational use. The atlas images in this article may not be removed from this article, nor reproduced, nor distributed, outside of the context of this article, for scholarly, education or commercial purposes, without the expressed permission of the Josephinum.

\section{Conflict of Interest Statement}

The Journal of Biocommunication Management Board and Editors believe that transparency in academic research is essential. Our $J B C$ authors are now required to disclose any possible conflict of interest when submitting a manuscript. In accordance with the Journal of Biocommunication's editorial policy, no potential conflict of interest has been reported or declared by this author. 